\title{
HUMAN RESOURCE MANAGEMENT dalam Meningkatkan Mutu Dosen PTKIS
}

\begin{abstract}
Ahmad Fauzi*
Abstract

The existence of Islamic education today, facing various problems ranging from the foundational and operational, and can not be resolved properly. This condition certainly draws a lot of attention among practitioners and managers of Islamic education to be neatly disentangled and can be found the tip of the base. The various problems, in the background by the government's policy on the higher education system by applying at least every course of study, must have six lecturers in accordance with their area of expertise, coupled with the urge to immediately transfer status. This condition on the one hand will have a positive and negative impact. Therefore, this paper briefly aims to parse the problem, through the approach of human resource management for Islamic higher education in improving the quality of human resources. Due to the quality of human resources, it can significantly impact the institutional management system and graduate quality especially for PTKI. Management of human resources is the most important aspect in the management system, therefore the function of MSDM must be optimally implemented in accordance with the needs and objectives of the organization to give birth to the quality of Islamic higher education. In addition, the management of human resources is expected to pay attention to the recruitment process recruitment and open competition, through planning, organizing, implementing and evaluating, so as to give birth to the quality of PTKI ready to compete in the midst of globalization era.
\end{abstract}

Keywords; human resource management, and the quality of PTKIS lecturers

\footnotetext{
* Dosen Fakultas Tarbiyah Institut Ilmu Keislaman Zainul Hasan Genggong Probolinggo Jawa Timur
} 


\section{A. Pendahuluan}

Sebagai agen peradaban dan perubahan, pendidikan tinggi Islam berada dalam atmosfir modernisasi dan globalisasi, kondisi ini menuntut PTKIS untuk memainkan perannya secara dinamis dan proaktif ditengah pertarungan global. Karena itu, peran pendidikan tinggi Islam diharapkan dapat memberikan kontribusi secara signifikan serta perubahan positif bagi perbaikan dan kemajuan peradaban Islam di masa depan, baik pada tataran intelektual teoritis maupun praktis. Pendidikan tinggi Islam, tidak hanya sekedar proses transformasi ilmu pengetahuan, tetapi bagaimana kehadiran pendidikan Islam juga mampu membentengi diri dari akses negatif globalisasi dan modernisasi, melalui pengembangan ilmu pengetahuan berbasis pada tradisi keilmuan klasik melalui integratif dan interkonektif, sebagai usaha untuk membangun kembali tradisi keilmuan pendidikan tinggi Islam sesuai harapan masyarakat dewasa ini. Karena itu pendidikan Islam saat ini berada pada kondisi yang lebih menekankan aspek doktriner-normatif dan cenderung ekslusif-apologetis, sebagaimana dijelaskan oleh Syafi'i Ma'arif, seperti yang dikutip Shofan bahwa potret pendidikan Islam telah melahirkan dua pola pemikiran yang bersifat kontradiktif, keduanya mengambil bentuk yang berbeda, baik pada aspek materi, sistem pendidikan maupun kelembagaan. ${ }^{1}$ Kedua model dimaksud, pendidikan Islam bercorak tradisionalis dan pendidikan Islam bercorak modernis ${ }^{2}$

Terlepas dari kontek tersebut, pendidikan tinggi Islam mengalami ambivalensi orientasi $^{3}$ dengan lahirnya paradigma dikotomis ${ }^{4}$ yang kemudian dapat menyebabkan lemahnya mutu pendidikan tinggi Islam, karena dianggap tidak mampu membaca pasar (market signal) dan hanya dikembangkan pada level institusional. Dengan memberikan peluang bagi pendidikan tinggi Islam untuk membuka berbagai macam jurusan dan program studi, tetapi semangat tersebut tidak mampu diimbangi dengan lahirnya mutu lulusan apalagi pada level keilmuan sebagaimana dimaksud. Karena berbagai problem pendidikan tinggi Islam bersifat kompleks dan menjadi sebuah sigklus negatif dalam sistem pengelolaan pendidikan tinggi Islam, karena hal tersebut tidak dapat diimbangi dengan manajemen sumber daya manusia (human resource management), ${ }^{5}$ terlebih bagi pendidikan tinggi keagamaan Islam swasta. Demikian kalau kita mencermati gelombang perubahan, keberadaan PTKI menjadi bagian integral dari peradaban Islam masa depan sebagaimana dampak globalisasi itu sendiri, ilmu pengetahuan dan teknologi merupakan motor dan penggerak globalisasi maka pendidikan tinggi harus peka dan berperan aktif dalam menyikapi perubahan tersebut. ${ }^{6}$

\footnotetext{
${ }^{1}$ Moh. Shofan, Pendidikan Berparadigma Profetik, (Yogyakarta: IRCiSoD, 2004), h. 6.

${ }^{2}$ Hujair AH. Sanaky, Paradigma Pendidikan Islam: Membangun Masyarakat Madani Indonesia, (Yogyakarta: Safiria Insani Press, 2003), h. 97-98.

${ }^{3}$ Saifuddin, Desekularisasi Pemikiran, (Bandung: Mizan, 1998), h. 103.

${ }^{4}$ Shofan, Islamisasi Ilmu Pengetahuan, dalam Logos, Jurnal Ilmu-Ilmu Sosial dan Humaniora, Vol.4, No.1 Januari 2005.

${ }_{6}^{5}$ Malik Fadjar, Madrasah dan Tantangan Modernitas, (Mizan: Bandung, 1998), h. 90

${ }^{6}$ Fadjar Dkk, Horison Baru Pengembangan Pendidikan Islam, Upaya Merespon Masyarakat Global. ( Malang: UIN Press 2004), h 131-133
} 
Demikian, pendidikan tinggi keagamaan Islam dewasa ini, terus bergulir sesuai dengan perkembagan globalisasi untuk menjawab kebutuhan masyarakat. Pandangan ini secara kuantitas merupakan hal yang sangat memgembirakan bagi sebagian masyarakat, namum secara kualitas mutu pendidikan tinggi Islam masih dipertanyakan kembali, dari sisi input dapat dilihat dari kapasitas dan daya tampung yang semakin banyak diminati, sebagaimana kondisi ini ditandai dengan dibukanya berbagai Jurusan dan program studi ditambah lagi dengan peraturan Kementerian Agama RI yang memberikan sinyal positif bagi PTKIS untuk melakukan perubahan atau alih status dari Sekolah Tinggi ke Institut dan Institut ke Universitas. Peluang ini secara signifikan memberikan dampak positif, tetapi juga memberikan dampak negatif pada aspek yang lainnya. Secara sosial dampak positif tersebut, kehadiran pendidikan tinggi Islam dipandang dapat melakukan berbagai terobosan diberbagai bidang terutama pada ilmu pengetahuan. Sebagaimana pandangan awal bahwa pendidikan tinggi Islam hanya difokuskan pada tradisi keilmuan klasik atau keagamaan saja. Tetapi dengan perkembangan tersebut, potret pendidikan tinggi Islam diharapkan dapat melakukan pengembangan pada level keilmuan ke yang lebih tinggi. Sedangkan dampak negatif, eksistensi pendidikan tinggi Islam masih dipandang lemah, karena pendidikan Islam belum mampu melakukan pembenahan secara manajerial, baik pada pengelolaan kualitas sumber daya manusia maupun jejaring sosial yang dibangun

Demikian, pengelolaan mutu selama ini menyedot perhatian banyak tokoh dalam pendidikan Islam, dikatakan bahwa lemahnya mutu pendidikan Islam selama ini banyak dipengaruhi beberapa faktor, sebagimana dikemukakan Sikun Pribadi, bahwa lemahnya mutu pendidikan secara universal banyak disebabkan oleh beberapa faktor, antara lain; lemahnya penelitian ditingkat para dosen, refrensi yang dijadikan pegangan para dosen pada pembelajaran belum diapdate, disamping lemahnya pengelolaan perguruan tinggi. ${ }^{7}$ Karena itu, manajemen sumber daya manusia (human resource management) pada level pendidikan tinggi Islam menjadi perhatian penting untuk dapat diurai dan dibahas dalam tulisan ini. Potret pendidikan tinggi Islam bertujuan untuk dapat meningkatakan kualitas SDM sebagaimana hal ini yang dikemukakan oleh Francis $\mathrm{Wahono}^{8}$, bahwa pendidikan secara universal bertujuan untuk melahirkan keterampilan, penanaman nilai-nilai sosial, alat pembentukan kesadaran suatu bangsa, memberikan warna bagi peningkatan kualitas keimanan dan ketaqwaan seseorang dalam upaya untuk dapat mengimbangi kemajuan ilmu pengetahuan dan teknologi dewasa ini. Keseimbangan antara imtaq dengan iptek diharapkan agar dapat menghasilkan cendekiawan muslim yang memiliki rasa tanggung jawab dunia dan akhirat.

Potret pendidikan tinggi Islam dalam pengembangannya harus berorientasi pada masa depan (future oreiented university), ${ }^{9}$ dengan mempersiapkan lulusan PTKI yang kompetitif dan berdaya saing menghadapi tantangan global serta mampu memikul tugas dan tanggung jawab di bidang keilmuan masing-masing, karena mahasiswa tidak dapat

\footnotetext{
${ }^{7}$ Sikun Probadi, Mutiara-Mutiara Pendidikan (Jakarta: PT Erlangga 1987), h 111.

${ }^{8}$ Francis Wahono, Kapilatisme Pendidikan Antara Kompeisi dan Keadilan, (Jakarta: Pustaka Pelajar, 2001), h 3

${ }^{9}$ Francis Wahono, Kapilatisme Pendidikan Antara Kompeisi.............. 133.
} 
hidup dengan iklim sama pada saat ini, demikian pendidikan tinggi Islam harus mempu menagkap perubahan dengan perkembangan ilmu pengetahuan yang semakin pesat dan cepat. Demikian masalah mutu pendidikan harus betul-betul menjadi agenda besar bagi PTKIS dan PTKIN melalui pengelolaan manajemen sumber daya manusia dosen pada pendidikan tinggi dimaksud. Karena kualitas dosen sangat strategis dan menjadi sebuah kunci peningkatan kualitas lulusan. Karena kualitas dosen harus memperoleh perhatian dan penangan yang serius dari penyelenggaran pendidikan tinggi Islam.

\section{B. Pembahasan}

\section{Paradigma Manajemen Sumber Daya Manusia}

Secara umum, manajemen sumber daya manusia (human resource management) sejak beberapa dekade terakhir terakhir menjadi bahan kajian yang terus dibahas, karena itu pembahasan ini menempati posisi strategis dalam sistem organisasi, termasuk dalam pendidikan tinggi keagamaan Islam untuk dapat diurai dan ditemukan ujung pangkalnya bagaimana model pengelolaan manajemen sumber daya manusia tersebut, sebagaimana dijelaskan Samsul Hadi dalam penelitiannya ${ }^{10}$, bahwa pengembangan mutu pendidikan hakikatnya berada pada pengelolaan sumber daya manusia, sebagai komponen utama dan pertama dalam iklim organisasi, karena itu penelitian Samsul Hadi dimaksud lebih memfokuskan kajiannya pada peningkatan mutu sumber daya manusia. Demikian hal yang sama juga dilakukan Suhadi Winoto dalam penelitiannya mengenai manajemen peningkatan mutu sumber daya manusia yang menjadi bahan kajian penting dalam pesantren. ${ }^{11}$ Demikian pengelolaan sumber daya manusia pada kelembagaan pendidikan Islam menjadi bahan kajian yang cukup serius, karena eksistensi SDM secara signifikan dapat mempengaruhi terhadap budaya kinerja serta peningkatan mutu pendidikan Islam.

Pada konteks tersebut, peran sumber daya manusia menjadi faktor utama dalam budaya organisasi, karena keberadaannya menjadi penentu lahirnya mutu pendidikan Islam. Pandangan tersebut, sebagaimana dikemukakan A.F. Stoner bahwa, manajemen sumber daya manusia secara universal merupakan sebuah proses berkelanjutan untuk menempatkan diri setiap individu pada jabatan yang tepat dalam organisasi. Demikian peran dan tindakan sosial individu dalam pendidikan tinggi Islam harus mampu dikelola melalui manajemen sumber daya manusia, dengan beberapa pendekatan, antara lain; a) pengadaan sumber daya manusia yang berkualitas di lingkungan PTKIS, melalui proses rekrutmen, seleksi, penempatan dan pengembangan-nyai sesuai dengan kebutuhan dan tuntutan masyarakat; b) pengembangan sumber daya manusia, melalui peningkatan dan ketrampilan secara

${ }^{10}$ Samsul Hadi HM, Strategi pengembagan Mutu Sumber Daya Guru di Lembaga Pendidikan Islam, (Malang: PPs UIN, 2002 ), h 2

${ }^{11}$ Suhadi Winoto, Implementasi Manajemen Peningkatan Mutu Berbasis Sekolah (MPMBS) Study Kasus di SLTP 1 Pandaan Pasuruan, (Malang: PPs UM 2007), h 1-10 
teknis, teoritis dan konseptual melalui pelatihan sesuai kebutuhan; c) pengintegrasian, kegiatan ini bertujuan untuk mempersatukan kepentingan organisasi dan kebutuhan sumber daya manusia, sehingga tercipta iklim kerjasama yang saling menguntungkan. Pada konteks tersebut, pengintegrasian menjadi bagian penting dalam manajemen sumber daya manusia, karena dipandang dapat mempersatukan kepentingan yang berbeda antara individu dan organisasi sangat sulit.

Demikian manajemen sumber daya manusia (human resource management), memegang peranan penting terhadap keberhasilan organisasi, sebagaimana pandangan tersebut dikemukakan oleh Buchari Zainun, ${ }^{12}$ bahwa manajemen sumber daya manusia merupakan bagian utama di dalam meningkatkan mutu pendidikan tinggi Islam, karena segala aktifitas kegiatan yang dibangun melalui tindakan dan peran sosial individu dapat diidentik dengan sistem manajemen. Demikian keberadaan sumber daya manusia bagi pendidikan tinggi Islam harus dapat direncanakan melalui proses perencanaan, pengorga nisasian dan pengevaluasian dalam pencapaian sebuah tujuan organisasi. ${ }^{13}$ Pada konteks tersebut, tentu tidak lepas dari proses rekrutmen (recruitment) sumber daya manusia melalui proses seleksi bersifat terbuka (open competition) sesuai standar mutu yang ada. Pada tahapan recruitment dimaknai bahwa pengadaan SDM, dilakukan untuk mengisi formasi dalam organisasi, melalui perencanaan, pengumuman, pelamaran, penyaringan sampai dengan pengangkatan dan penempatan. Pengdaan SDM dimaksud, dipandang sebagai proses pemanfaatan berbagai sumber daya atau potensi yang dimiliki oleh masing-masing individu. Pada konteks tersebut rekrutmen sumber daya manusia dalam organisasi, dilakukan melalui recruitment from outside dan recruitment from within. Pada recruitment from within dapat dipersepsikan sebagai upaya pemanfatan SDM yang sudah ada dalam organisasi, pandangan ini dilakukan melalui pemindahan dengan cara promosi atau tanpa promosi. Sedangkan proses pengadaan sumber daya manusia dari luar tahapan seleksi memegang peran penting dan proses seleksi dilakukan dan bersifat terbuka (open competition) yang didasarkan kepada standar dan mutu yang sifatnya dapat diukur (measurable).

Pemeliharaan (maintenance) merupakan tanggung jawab bagi seorang pemimpin dengan disertai ganjaran (reward system) yang diberikan kepada setiap individu dalam organisasi, agar tindakan individu dimaksud, mampu bertahan dan dapat meningkatkan peran nya secara optimal. Pendekatan ini digunakan dalam rangka untuk memelihara sumber daya manusia, mendorong meningkatkan serta mengembangkan produktivitas kerja. Sedangkan pengembangan (development) sumber daya manusia pada konteks pendidikan tinggi Islam hanya dapat 2011), h.90.

${ }^{12}$ Zainun, Buchari. Manajemen Sumber Daya Manusia Indonesia, (PT Gunung Agung, Jakarta,

${ }^{13}$ Notoatmodjo, Soekidjo, Pengembangan Sumber Daya Manusia, (PT Gunug Agung Jakarta, 1992), h. 29 
dilaksanakan melalui proses pendidikan, pelatihan terutama yang menyangkut pengembangan intelektualitas dan kepribadian. Karena itu, pengembangan tersebut, dapat dilakukan melalui analisis kebutuhan (need assessment) antara lain ; 1) analisis internal, bagaimana organisasi melakukan pelatihan, 2) analisis pekerjaan, apa yang harus diajarkan agar setiap individu dapat melaksanakan tugas-nya, 3) analisis kepribadian, siapa yang membutuhkan pendidikan dan pelatihan. Ketiga aspek tersebut dapat meningkatkan kemampuan individu dalam organisasi dan terciptan kualitas sumber daya manusia yang berdaya saing tinggi.

\section{Peran Strategis SDM dalam Meningkatkan Mutu Dosen PTKIS}

Dalam meningkatkan mutu dosen di lingkungan PTKIS, pengelolaan pendidikan tinggi Islam harus lebih selektif dalam proses rekrutmen, melalui sistem manajemen yang transformatif. Karena mutu SDM akan menjadi penentu lahirnya mutu pendidikan tinggi Islam, sesuai dengan tuntutan dan harapan masyarakat pada umumnya. Demikian potret SDM dalam pendidikan Islam masa depan, mempunyai peran strategis, sekaligus menjadi pioner bagi PTKIS, untuk memberikan respon terhadap perubahan sesuai den kebutuhan stakeholders. Pendidikan tinggi Islam harus memiliki SDM yang profesional dan kompeten sesuai bidang keilmuannya masing-masing, secar prosedural pengelolaan manajemen sumber daya manusia dapat dilakukan melalui beberapa langkah antara lain: 1) penarikan (rekrutmen), proses ini merupakan bagian utama dalam mendapatkan SDM bagi PTKIS, berdasarkan analisis kebutuhan internal kelembagaan, untuk mengisi posisi dan jabatan struktural PTKIS, melalui seleksi administratif dan kamampuan personal dosen. Pada konteks tersebut, penarikan dapat juga ditafsirkan sebagai proses pencarian SDM dengan berbagai kemampuan yang dimiliki oleh masing-masing individu $^{14}$ sesuai kebutuhan organisasi; 2) seleksi, proses ini dilakukan setelah masing-masing personal memenuhi beberapa persyarakat dan hal ini dilakukan untuk mengetahui kemampuan serta keilmuan masing-masing individu, dengan tujuan untuk mendapatkan sumber daya manusia yang memenuhi dan memiliki kualifikasi akademik; ${ }^{15}$ 3) pembinaan, proses ini

bertujuan untuk mengembangkan kemampuan sumber daya manusia khususnya dalam menjalankan tugasnya, karena itu SDM dalam internal PTKIS perlu adanya pembinaan secara berkesinambungan. Demikian pembinaan merupakan proses bimbingan untuk menjamin masing-masing seumber daya manusia SDM dapat memiliki kemampuan yang berkompeten; 4) pemberhentian, dalam konteks manajemen sumber daya manusia pemberhentian adalah fungsi operatif terakhir manajemen sumber daya manusia. Karena itu pemberhentian merupakan pemutusan

${ }^{14}$ Robbins, Stephen P. and Timothy A. Judge, Organizational Behavior. (New Jersey : Pearson Prentice Hall, 2009), h. 80.

${ }^{15}$ Mangkunegara, Anwar Prabu Manajemen Sumber Daya Manusia Perusahaan. (Bandung: PT Remaja Rosdakarya. 2010), h. 6 
hubungan kerja bagi dosen PTKIS yang dapat disebabkan berbagai alasan. Pada aspek yang lain pemberhentian dapat dilakukan oleh beberapa hal, yaitu; pensiun, permintaan bagi personal dosen, pemberhentian langsung oleh organisasi PTKIS dan pemberhentian sementara ${ }^{16}$

\section{Strategi Pengelolaan Mutu Dosen di Lingkungan PTKIS}

Pengelolaan sumber daya manusia bagi dosen di lingkungan PTKIS tidak hanya bertujuan untuk memenuhi kebutuhan SDM tetapi juga peningkatan mutu SDM yang memiliki daya saing sesuai dengan kebutuhan masyarakat. Karena itu, sumber daya manusia merupakan salah satu faktor terpenting dalam organisasi pada pendidikan tinggi Islam. Demikian berbagai upaya peningkatan SDM dapat dilakukan melalui beberapa strategi dalam pengelolaan pendidikan tinggi Islam, melalui proses perencanan (human resource planning) sesuai kebutuhan organisasi. Perencanaan SDM merupakan seperangkat proses dan aktivitas yang dilakukan seorang pemimpin untuk meningkatkan mutu dosen dilingkungan PTKIS. Karena itu, perencanaan sumber daya manusia harus disesuaikan dengan strategi tertentu agar tujuan PTKIS dapat tercapai.

Demikian peningkatan SDM secara terus menerus dapat ditingkatkan, sesuai kebutuhan masyarakat dewasa ini. ${ }^{17}$ Beberapa faktor yang mempengaruhi perubahan tersebut yaitu; globalisasi, ilmu pengetahuan dan teknologi. Perubahan tersebut, secara signifikan dapat memberikan pengaruh bagi peningkatan mutu sumber daya manusia, dengan melakukan proses perencaraan dan pengembangan sumber daya manusia. Perencanaan SDM dapat dilakukan dengan cara mengevaluasi keefektrifan beberapa program untuk memenuhi kebutuhan organisasi. Karena itu perencanaan sumber daya manusia merupakan langkah strategis untuk melahirkan mutu SDM baik secara kualitatif maupun kuantitatif melalui tahapan tertentu. ${ }^{18}$ Pada konteks tersebut perencanaan sumber daya manusia dimaksud harus disesuaikan dengan kebutuhan kelembagaan, melalui serangkaian program untuk dapat mengantisipasi permintaan masyarakat terhadap peningkatan mutu pendidikan tinggi Islam. Demikian pengembangan SDM tersebut, merupakan serangkaian kegiatan yang dilakukan secara sistematis dan strategis untuk memehuni kebutuhan organisasi ${ }^{19}$ bersama sama dengan team dan manajer guna meningkatkan kinerja dan menghasilkan keunggulan dan berdaya saing. Pada konteks tersebut, perencanaan SDM bagi dosen PTKI bertujuan untuk memastikan bahwa orang yang berada dalam organisasi berada pada tempat yang tepat (the right man on the right place). Karena proses perencanaan SDM dalam pendidikan tinggi

\footnotetext{
${ }^{16}$ Mutiara S. Panggabean, Manajemen Sumber Daya Manusia, (Bogor: Ghalia Indonesia, 2009), h.78.

${ }^{17}$ Nursanti, T.Desy, Strategi Teintegrasi Dalam Perencanaan SDM , dalam Usmara, A (ed), Paradigma Baru Manajemen Sumber Daya Manusia, (Yogyakarta, Amara books, 2002), h. 90

${ }^{18}$ Schuler. R.S., \& Walker, J.W, Human Resource Strategy: Focusing on Issues and Actions. Organizational Dynamics, (New York, West Publishing Company, 1990), h. 21

${ }^{19}$ Malayu S. P. Hasibuan, Manajemen Sumber Daya Manusia, (PT Bumi Aksara, Jakart:2007, Cet. 9), h. 284
} 
Islam, dapat dibagi menjadi beberapa teknik, yaitu; 1) strategic planning; perencanaan yang bertujuan untuk mempertahankan kelangsungan organisasi dalam menghadapi persaingan global, 2) operational planning, menunjukkan permintaan terhadap mutu SDM dalam pendidikan Islam, 3) human resources planning, perencanaan sumber daya manusia (human resource management) dan dilakukan dalam jangka pendek, menengah dan jangka panjang melalui beberapa kebijaksanaan dalam organisasi. Demikian perencanan pengembangan sumber daya manusia bagi pendidikan tinggi keagamaan Islam perlu diintegrasikan untuk memudahkan organisasi melakukan berbagai tindakan yang diperlukan, serta mengevaluasi keseluruhan SDM dalam proses pencapaian tujuan.

Pengelolaan sumber daya manusia merupakan aspek penting dalam pendidikan Islam, karena itu fungsi pengelolaan sumber daya manusia harus dilaksanakan secara optimal sehingga tujuan individu dan organisasi dapat tercapai. Disamping itu dengan prosedur pengelolaan sumber daya manusia yang baik diharapkan problem yang sedang dihadapi oleh PTKI dapat teratasi, melalui proses rekrutmen, seleksi dan perencanaan, pengorganisasian, pengerahan, pengendalian, pengadaan, pengembangan, kompensasi, pengintegrasian, pemeliharaan, kedisiplinan, dan pemberhentian.

\section{Manajemen SDM dalam Peningkatan Mutu Dosen PTKI}

Pengelolaan mutu pendidikan Islam, secara universal terus ditingkatkan sesuai kebutuhan kelembagaan. Karena pada hakikatnya lulusan PTKI secara signifikan akan memberikan tolak ukur terhadap SDM pada kelembagaan dimaksud. Berdasarkan hasil penelitian sejak beberapa tahun terakhir kualitas SDM pada pendidikan secara umum menempati peringkat ke-110 di dunia, ditambah lagi dengan kondisi SDM Indonesia di Asia Tenggara ketinggalan dari negara-negara tetangga, seperti; Singapora, Brunai dan Malaysia ${ }^{20}$. Pada aspek yang lain, hasil Tes Internasional komprehensip yang dilakukan oleh organization for economic cooperation and development, yang dikenal dengan PISA (programme for international student assessment), kualitas daya serap membaca masyarakat Indonesia berada pada peringkat ke-39, sedangkan dibidang Saince berada pada urutan ke-39. Demikian potret SDM di Indonesia masih ketinggal jauh dibanding kan dengan beberapa negara, kondisi ini menjadi bagian penting bagi sistem pendidikan terutama pada pendidikan tinggi Islam, secara terus menerus dapat meningkatkan mutu sumber daya manusia di Indonesia.

Berangkat dari konteks tersebut, kehadiran pendidikan tinggi Islam memiliki peran utama dalam meningkatkan kualitas SDM, karena itu upaya untuk peningkatan mutu dosen di tingkat PTKI dipandang penting untuk dilakukan perbaikan secara terus-menerus (continuous improvement), melalui proses

\footnotetext{
${ }^{20}$ Sumber: UNDP-Human Development Report 2005
} 
rektutmen, seleksi, penempatan dan pengembangan sumber daya manusia (human resource development). Secara universal mutu dapat dimaknai dengan keunggulan baik pada proses pengelolaan, maupun out-put yang dihasilkan sesuai dengan kebutuhan masyarakat pada umumnya, Karena itu untuk mendeskripsikan dan menjelaskan mutu yang diinginkan akan tampak perbedan standar yang mereka gunakan dalam memaknai mutu tersebut, demikian mutu dalam pandangan seseorang belum tentu sama dengan mutu menurut pandangan orang lain, terjadinya perbedaan tersebut, dilatarbelakangi oleh landasan filosofis yang mereka bangun. Pada konteks tersebut, mutu dalam perspektif Deming, terletak pada proses pengelolaan pada semua komponen dalam internal organisasi terutama manajemen sumber daya manusia di lingkungan PTKI malalui plan, do, check dan action. Sedangkan menurut Juran, beberapa aspek manajemen mutu yang tidak terlalu bersifat statistik, tetapi mutu dapat dikembalikan kepada kepuasan pelanggan, karena itu untuk mencapai mutu dibutuhkan sebuah proses perencaraan, penetapan sasaran, isu-isu organisasi, kebutuhan penetapan tujuan sasaran untuk perbaikan secara berkelanjutan. Bahkan lebih lanjut ia menjelaskan bahwa strategi peningkatan mutu terdiri dari beberapa komponen antara lain: 1) manajer senior yang memiliki pandangan strategis tentang organisasi, 2) manajer yang memiliki pandangan operasional tentang mutu, 3) setiap individu yang memiliki tanggung jawab terhadap mutu. ${ }^{21}$ Sedangkan Goetsch dan Davis mendefinisikan mutu sebagai kondisi yang dinamis dan berhubungan dengan produk, jasa, proses yang mempengaruhinya ${ }^{22}$.

Demikian pengelolaan mutu dosen PTKI terus mengalami perubahan, terutama pada paradigma yang dikembangkan dengan cara menerapkan konsep manajemen yang bersifat bottom up pada fokus peningkatan SDM. ${ }^{23}$ Karena itu paradigma tersebut harus digunakan sebagai acuan peningkatan mutu PTKI yang dimulai dari pengelolaan SDM, karena kualitas sumber daya manusia merupakan inti seluruh sistem dalam organisasi. Demikian eksistensi SDM dalam manajemen pengelolaan menjadi bagian penting untuk meningkatkan mutu PTKI melalui pengadaan, rekrutmen SDM

\section{Penutup}

Manajemen sumber daya manusia dalam pendidikan tinggi Islam merupakan aspek terpenting dalam menigkatkan mutu pendidikan Islam. Karena kualitas SDM, secara signifikan dapat memberikan dampak terhadap sistem pengelolaan kelembagaan dan kualitas lulusan terutama bagi PTKI. Pengelolaan sumber daya manusia merupakan

${ }^{21}$ Cortada, J.W, TQM For Information Systems Management. Total Quality Management Terapan dalam Manajemen Sistem Informasi. (Terjemehan Eko Suwardi.1996.Yogyakarta, 1996), h. 90. Cet. 9), h. 284

${ }^{22}$ Malayu S. P. Hasibuan, Manajemen Sumber Daya Manusia, (PT Bumi Aksara, Jakart:2007,

${ }^{23}$ Muhaimin, Manajemen Penjaminan Mutu di Universitas Islam Negeri Malang, (Malang: UIN Press, 2005), h 9 
aspek terpenting dalam sistem manajemen, karena itu fungsi MSDM harus dapat dilaksanakan secara optimal sesuai dengan kebutuhan dan tujuan organisasi untuk melahirkan mutu pendidikan tinggi Islam. Disamping itu, pengelolaan sumber daya manusia diharapkan dapat memperhatikan proses rekrutmen (recruitment) dan bersifat terbuka (open competition), melalui perencanaan, pengorganisasian, pelaksanaan dan pengevaluasian, sehingga melahirkan mutu PTKI yang siap bersaing di tengah-tengah globalisasi. Demikian manajemen sumber daya manusia (human resource management) harus mampu direncanakan secara optimal sesuai dengan kebutuhan insitusi, dengan tidak mudah merekrutmen sumber daya manusia, tetapi melalui proses seleksi bersifat terbuka (open competition) sesuai standar mutu yang ada, melalui analisis kebutuhan (need assessment) antara lain ; 1) analisis internal, bagaimana organisasi melakukan pelatihan, 2) analisis pekerjaan, apa yang harus diajarkan agar setiap individu dapat melaksanakan tugas-nya, 3) analisis kepribadian, siapa yang membutuhkan pendidikan dan pelatihan. Ketiga aspek tersebut dapat meningkatkan kemampuan individu dalam organisasi dan terciptan kualitas sumber daya manusia yang berdaya saing tinggi. 


\section{Daftar Pustaka}

Cortada, J.W, TQM For Information Systems Management. Total Quality Management Terapan dalam Manajemen Sistem Informasi. (Terjemehan Eko Suwardi.1996.Yogyakarta, 1996)

Fadjar Dkk, Horison Baru Pengembangan Pendidikan Islam, Upaya Merespon Masyarakat Global. ( Malang: UIN Press 2004)

Francis Wahono, Kapilatisme Pendidikan Antara Kompeisi dan Keadilan, (Jakarta: Pustaka Pelajar, 2001), h1-3

Hujair AH. Sanaky, Paradigma Pendidikan Islam: Membangun Masyarakat Madani Indonesia, (Yogyakarta: Safiria Insani Press, 2003)

Malayu S. P. Hasibuan, Manajemen Sumber Daya Manusia, (PT Bumi Aksara, Jakart:2007, Cet. 9)

Malayu S. P. Hasibuan, Manajemen Sumber Daya Manusia, (PT Bumi Aksara, Jakart:2007, Cet. 9)

Malik Fadjar, Madrasah dan Tantangan Modernitas, (Mizan: Bandung, 1998)

Mangkunegara, Anwar Prabu Manajemen Sumber Daya Manusia Perusahaan. (Bandung: PT Remaja Rosdakarya. 2010)

Moh. Shofan, Pendidikan Berparadigma Profetik, (Yogyakarta: IRCiSoD, 2004)

Muhaimin, Manajemen Penjaminan Mutu di Universitas Islam Negeri Malang, (Malang: UIN Press, 2005)

Mutiara S. Panggabean, Manajemen Sumber Daya Manusia, (Bogor: Ghalia Indonesia, 2009)

Notoatmodjo, Soekidjo, Pengembangan Sumber Daya Manusia, (PT Gunug Agung Jakarta, 1992)

Nursanti, T.Desy, Strategi Teintegrasi Dalam Perencanaan SDM , dalam Usmara, A (ed), Paradigma Baru Manajemen Sumber Daya Manusia, (Yogyakarta, Amara books, 2002)

Robbins, Stephen P. and Timothy A. Judge, Organizational Behavior. (New Jersey : Pearson Prentice Hall, 2009)

Saifuddin, Desekularisasi Pemikiran, (Bandung: Mizan, 1998).

Samsul Hadi HM, Strategi pengembagan Mutu Sumber Daya Guru di Lembaga Pendidikan Islam, (Malang: PPs UIN, 2002 ) 
Schuler. R.S., \& Walker, J.W, Human Resource Strategy: Focusing on Issues and Actions. Organizational Dynamics, (New York, West Publishing Company, 1990)

Shofan, Islamisasi Ilmu Pengetahuan, dalam Logos, Jurnal Ilmu-Ilmu Sosial dan Humaniora, Vol.4, No.1 Januari 2005.

Sikun Probadi, Mutiara-Mutiara Pendidikan (Jakarta: PT Erlangga 1987)

Suhadi Winoto, Implementasi Manajemen Peningkatan Mutu Berbasis Sekolah (MPMBS) Study Kasus di SLTP 1 Pandaan Pasuruan, (Malang: PPs UM 2007)

Sumber: UNDP-Human Development Report 2005

Zainun, Buchari. Manajemen Sumber Daya Manusia Indonesia, (PT Gunung Agung, Jakarta, 2011) 